\title{
İnlet patch olgularının retrospektif tek merkez değerlendirilmesi
}

\author{
A retrospective single-center evaluation of inlet patch cases
}

\author{
(D) Ali ŞENKAYA , (D) Ferit ÇELIK ${ }^{1}$, (D) Nalan Gülşen ÜNAL ${ }^{1}$, (D) Seymur ASLANOV ${ }^{1}$, (D) Murat SEZAK², \\ (D) Başak DOĞANAVŞARGİL YAKUT ${ }^{2}$, ID Ahmet Ömer ÖZÜTEMIZI ${ }^{1}$ \\ Ege Üniversitesi Tip Fakültesi, ${ }^{1}$ Gastroenteroloji Bilim Dalı, ${ }^{2}$ Patoloji Anabilim Dalı, Izmir
}

\begin{abstract}
Giriş ve Amaç: Inlet patch, üst özofagus sfinkterinde veya hemen distalinde yer alan heterotopik gastrik mukoza adasıdır. Bu çalışmada amaç kliniğimizde inlet patch tanısı konulan vakaların sıklığı, demografik, klinik ve endoskopik özelliklerini değerlendirmektir. Gereç ve Yöntem: Bu çalışma Ocak 2015- Mart 2020 tarihleri arasında Gastroenteroloji Bilim Dalında herhangi bir nedenle özofagogastroduodenoskopi yapılıp, inlet patch tanısı konulan 245 hastanın retrospektif değerlendirilmesini içermektedir. Çalışmaya alınan hastaların; yas, cinsiyet, endoskopi yapilma nedeni, inlet patch lezyonunun boyutu ve sayısı, Barrett özofagus, özofajit ve hiatus hernisi varlı̆ ve var olan patoloji sonuçları değerlendirilmiştir. Bulgular: Iki yüz kırk beş hastada inlet patch bulunmuştur. Iki yüz kırk beş hastanın 124'ü (\%50.6) kadın, yas ortalaması $48.64 \pm 14.54$ yıldır. Inlet patch boyutunun ortalaması $13.32 \pm 8.85$ (3-40) mm'dir. En sık endoskopi yapılma nedeni 91 (\%37.1) hastada dispepsi olarak saptanmıştır. Inlet patch saptanan hastaların endoskopi sirasinda 39'unda (\%15.9) özofajit, 20'sinde (\%8.2) hiatus hernisi ve 6’sında (\%2.4) Barrett özofagus görülmüștür. Hastaların 125'inden (\%51) biyopsi alınmış olup, 98 (\% 78.4) hastada patoloji ile uyumlu sonuçlanmıştır. Hastaların endoskopi yapılma nedenleri, Barrett özofagus ve hiatus hernis varlığı ile inlet patch boyutu arasındaki istatistiksel olarak anlamlı farklılık olduğu saptanmıştır (sırasılyla; $p=0.03, p=0.004$, p=0016). Sonuç: Herhangi bir nedenle yapılan endoskopilerin \%1.24'ünde inlet patch saptanmıştır. Merkezimiz üçüncü basamak bir sağlık kuruluşu olduğundan bu sonucun, Ege Bölgesi’nin inlet patch prevalansını yansıttığını düşünmekteyiz. Fonksiyonel dispepsi, disfaji, nedeni bilinmeyen kronik öksürügü ve globusu olan hastalarda, servikal özofagus inlet patch açısından dikkatli bir şekilde incelenmelidir.
\end{abstract}

Anahtar kelimeler: Heterotopik gastrik mukoza, inlet patch, dispepsi
Background and Aims: An inlet patch is an island of heterotopic gastric mucosa located in the upper or immediate distal part of the esophageal sphincter. The aim of this study was to evaluate the frequency, demographics, and clinical and endoscopic features of cases diagnosed with inlet patch in our clinic. Material and Methods: This retrospective study included 245 patients who underwent esophagogastroduodenoscopy for any reason in the department of gastroenterology between January 2015 and March 2020. The patients were evaluated on the basis of age, gender, reason for endoscopy, size and number of inlet patch lesions, presence of Barrett's esophagus, esophagitis and hiatus hernia, and pathology results, if available. Results: Inlet patch was found in 245 of the endoscopies performed for any reason. Of the 245 patients, 124 (50.6\%) were women, and the mean age was $48.64 \pm 14.54$ (19-81) years. The mean size of inlet patch was $13.32 \pm 8.85$ (3-40) $\mathrm{mm}$. Dyspepsia was found to be the most common reason for endoscopy in 91 (37.1\%) patients. Endoscopy revealed esophagitis in 39 (15.9\%), hiatus hernias in 20 (8.2\%), and Barrett's esophagus in 6 (2.4\%) patients among those detected to have inlet patch. A biopsy was taken from 125 (51\%) patients, and the result was consistent with the reported pathology in 98 (78.4\%) patients. A statistically significant difference was found between the inlet patch size and the reason for endoscopy, presence of Barrett's esophagus, and presence of hiatus hernia ( $p=0.03,0.004$, and 0.016, respectively). Conclusion: Inlet patch was detected in $1.24 \%$ of endoscopies performed. Since ours is tertiary healthcare providing center, we consider that this result reflects the inlet patch prevalence of the Ege region in Turkey. The cervical esophagus should be carefully examined for the possibility of inlet patch in patients with functional dyspepsia, dysphagia, chronic cough with an unknown cause, and globus. Endoscopy should be repeated using narrow-band imaging technique after fully sedating the patients even if endoscopy has been performed before.

Key words: Heterotopic gastric mucosa, inlet patch, dyspepsia

ve disfaji, globus, öksürük, boğaz ağrısı, ses kısıklığı, aşı1 boğaz temizlemeye neden olabilir. Bazı hastalarda asit sekresyonundan darlık oluşumuna sekonder özofagus daralması da görülebilir (2,3,6,7). En yaygın histolojik alt tipleri fundik mukoza ve kardiyak tip mukozadır (7-9). Tanı, Z hattından ayrı olarak ve Barrett özofagusuyla (BÖ) ilgisi olmayan, genellikle kesici dişlerden itibaren 15 ile 21. $\mathrm{cm}$ arasında bulunan ve çevredeki grimsi inci renkli özofagus mukozasından açıkça ayrılmış sınırları keskin, kadifemsi, gül veya somon renkli, oval veya yuvarlak bir yamanın endoskopide görülmesidir. IP boyutu mikroskopikten 5 cm'ye kadar değişir ve tek veya çoklu olabilir. Nadiren, polipoid tarif edilmiştir $(10,11)$. 
Bu çalışmada amaç kliniğimizde IP tanısı konulan vakalarının sıklığı, demografik, klinik ve endoskopik özelliklerini değerlendirmektir.

\section{GEREC ve YÖNTEM}

Bu çalışma; Ocak 2015-Mart 2020 tarihleri arasında Ege Üniversitesi Tip Fakültesi Gastroenteroloji Bilim Dalında herhangi bir nedenle özofagogastroduodenoskopi yapılan hastaların retrospektif tek merkezli irdelenmesini içermektedir. Bu tarihler arasında özofagogastroduodenoskopi yapilan 27390 hastadan 7622'si (tekrarlayan kontrol incelemeleri, hasta intolerasyonu nedeniyle tamamlanamayanlar, gıda artıkları ile dolu mide, verilerine tam ulaşlamayan) inceleme olması nedeniyle dışlanmıştır. Geriye kalan 19738 hastada 245 IP saptanmış ve incelemeye alınmıştır. Endoskopi raporlarından protokol numaralarına ulaşılarak hastane elektronik veri tabanından hasta bilgilerine ulaşılmıştır. Çalışmaya alınan hastaların; yaș, cinsiyet, endoskopi yapılma nedeni, IP lezyonunun boyutu ve sayısı, BÖ, özofajit ve hiatus hernisi varlığı ve varsa patoloji sonucu olgu rapor formuna kaydedilmiştir.

Endoskopik incelemeler, Olympus GIFHD 190 cihazı ile bir gastroenteroloji uzmanı veya onun nezaretinde gastroenteroloji yan dal asistanı ve endoskopi hemşiresi ile yapılmıştır. IP, kesici dişlerden itibaren üst özofagusta bulunan ve çevredeki grimsi inci renkli özofagus mukozasından açıkça ayrılmış, sınırları keskin, kadifemsi, gül veya somon renkli oval veya yuvarlak bir yamanın endoskopide görülmesi olarak tanımlanmıștır (10) (Resim 1). BÖ, özofagus alt bölgesinde normal skuamöz epitel yerine kolumnar epitelin yerleşmesi ve en az 1 $\mathrm{cm}$ dilcik ve dairesel şekilde uzanması olarak tanımlanmıștır (12). Özofajit Los Angeles smiflamasına göre, mukozal katlantilar üzerinde bir veya daha fazla $\leq 5 \mathrm{~mm}$ erozyon grade A,

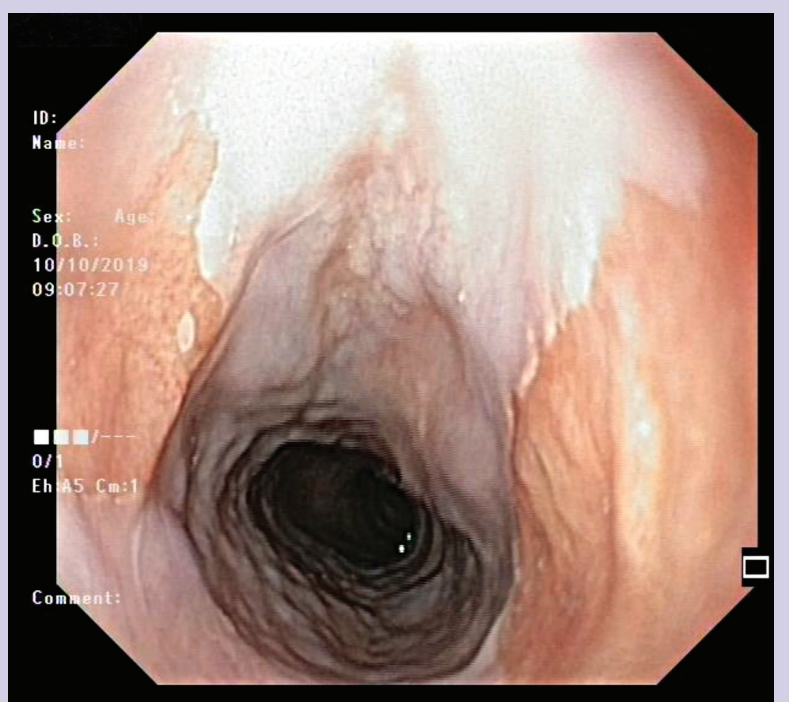

Resim 1. IP endoskopik görünümü (Görüntü Ege Üniversitesi Gastroenteroloji Bilim Dalı Endoskopi Ünitesi arşivinden alınmıştır.) IP: Inlet patch mukozal katlantılar üzerinde bir veya daha fazla $\geq 5 \mathrm{~mm}$ erozyon grade B, iki veya daha fazla erozyonlar arasında çevrenin \%75'ini geçmeyen birleşmeler grade C, çepeçevre özofagus alt ucu saran erozyonlar ise grade D olarak tanımlanmıştır (13). Hiatus hernisi, endoskopik olarak gastrik pililerin sonlanım noktasının Z çizgisine uzanması ve hiatus diafragmatikus ile özofagogastrik bileşkenin $\geq 3 \mathrm{~cm}$ olması olarak kabul edilmiştir. Biyopsi alındı ise biyopside kolumnar epitel ve/ veya eşlik eden intestinal metaplazinin varlığı IP ile uyumlu olarak kabul edilmiştir.

Çalışmada etik ilkelere uyulmuş ve çalışma için Ege Üniversitesi Tibbi Araştırmalar Etik Kurulundan 29.05.2020 tarih ve 20-5.1T/16 sayılı etik kurul onayı alınmıştır.

Yaş, boyut ve IP sayısı değişkenlerinin normal dağılıma uygunluğu görsel (histogram) ve analitik yöntemlerle (Kolmogorov Smirnov testi) incelenmiştir. Çalışmada toplanmış olan sayısal veriler ortalama, ortanca, standart sapma, en büyüken küçük değer; kategorik veriler ise oran, yüzde gibi tanımlayıcı yöntemlerle ifade edilmiştir. Değişkenlerin gruplara göre karşılaştırılması için Mann-Whitney U testi kullanılmıştır. Kategorik değişkenlerin gruplar arasındaki karşılaştırmaları için yerine göre Ki-kare ya da Fisher testleri (hücrelerde gözlenen değerlerin Ki-kare testi varsayımlarını sağlamadığı durumda) kullanılarak yapılmıştır. IP boyutunun en sık görülen semptomlara göre belirlenen gruplar arasındaki değişimi Kruskal Wallis testi kullanılarak karşışlaştırılmıştır. P değerinin 0.05 'in altında olduğu değerler istatistiksel olarak anlamlı kabul edilmiştir. Tüm istatistiksel analiz ve hesaplamalar için SPSS Statistics Ver. 22.0 programı kullanılmıştır.

\section{BULGULAR}

On dokuz bin yedi yüz otuz sekiz hastanın 245'inde (\%1.24) IP bulunmuştur. 245 hastanın 124'ü (\%50.6) kadın, 121'i (\%49.4) erkekti. Hastaların yaş ortalaması $48.64 \pm 14.54$ ylldır. IP boyutunun ortalamasi $13.32 \pm 8.85$ (3-40) $\mathrm{mm}$ ve sayısının ortalaması $1.30 \pm 0.60$ (1-4) saptanmışıı. Endoskopi yapılma nedenleri 91 (\%37.1) hastada dispepsi, 33 (\%13.5) hastada pirozis ve regürjitasyon, 32 (\%13.1) hastada epigastrik ağrı, 22 (\%9) hastada anemi, 19 (\%7.8) hastada disfaji, 13 (\%5.3) hastada malignite tetkik ve 12 (\%4.9) hastada varis kontrolüydü. IP saptanan hastaların endoskopi sırasında 39'unda (\%15.9) özofajit, 20'sinde (\%8.2) hiatus hernisi ve 6'sında (\%2.4) BÖ saptanmıştır. Hastaların 125 'inde (\%51) IP olduğu düşünülen alandan biyopsi alınmış olup, bu hastalarm 98'inin (\%78.4) patoloji sonucu IP ile uyumlu olduğu görülmüştür. Hastaların demografik, klinik ve endoskopik özellikleri Tablo l'de gösterilmiştir.

Hastaların en sik endoskopi yapılma nedenleri ve IP boyutu arasında istatistiksel olarak anlaml farklıllk olduğu saptanmıştır ( $\mathrm{p}=0.03$ ) (Tablo 2). Pirozis+regürjitasyon şikayeti ile yapılan endoskopilerde ortanca IP boyutu $(20 \mathrm{~mm})$ diğer nedenlere göre daha büyük saptanmıştır. 
BÖ ve hiatus hernisi varlığı ile IP boyutu arasında istatiksel olarak anlamlı ilişki saptanmıştır (sırasıyla $\mathrm{p}=0.004,0.016$ ) (Tablo 3).

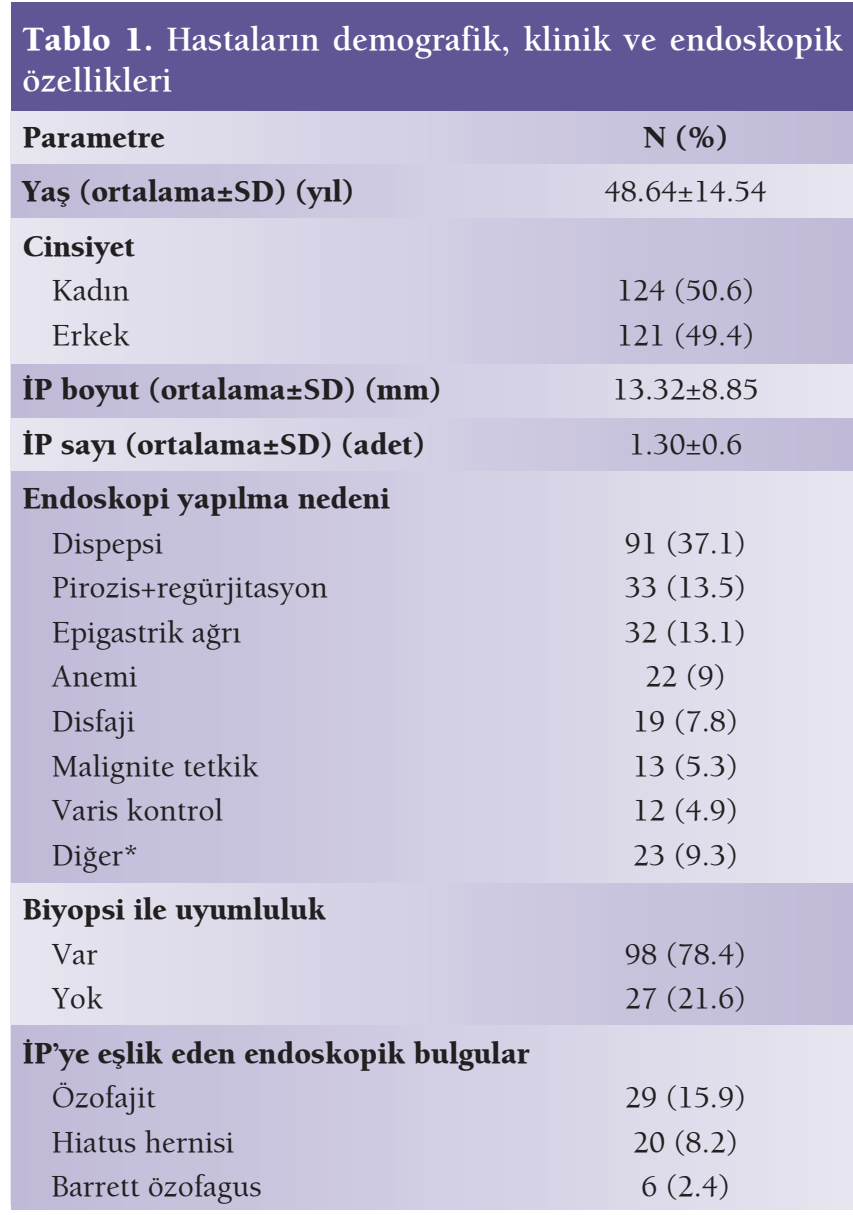

SD: Standart deviasyon, IP: Inlet patch, Diğer*: Kronik ishal $(\mathrm{n}=7)$, intestinal metaplazi ve atrofik gastrit takip $(n=7)$, gastrointestinal sistem kanaması $(n=6)$, globus (n=1), kilo kaybı $(\mathrm{n}=1)$, Barrett özofagus kontrolü $(\mathrm{n}=1)$.

Tablo 2. Endoskopi yapılma nedenleri ve IP boyutu arasındaki ilişki

\begin{tabular}{|c|c|c|}
\hline Semptom & $\begin{array}{l}\text { İP Boyutları (mm) } \\
\text { Ortanca (min-max) }\end{array}$ & $\mathbf{p}$ \\
\hline Dispepsi $(\mathrm{n}=91)$ & $10(4-40)$ & \multirow{8}{*}{0.030} \\
\hline Pirozis+regurjitasyon $(\mathrm{n}=33)$ & $20(3-40)$ & \\
\hline Epigastrik ağrı $(n=32)$ & $10(3-40)$ & \\
\hline Anemi $(n=22)$ & $9(4-25)$ & \\
\hline Disfaji (n=19) & $15(4-30)$ & \\
\hline Malignite tetkik (n=13) & $15(4-30)$ & \\
\hline Varis kontrol $(\mathrm{n}=12)$ & $5.5(4-20)$ & \\
\hline Diğer* $(n=23)$ & $10(4-35)$ & \\
\hline
\end{tabular}

IP: Inlet patch. Diğer*: Kronik ishal $(\mathrm{n}=7)$, intestinal metaplazi ve atrofik gastrit takip $(n=7)$, gastrointestinal sistem kanaması $(n=6)$, globus $(n=1)$, kilo kaybı $(\mathrm{n}=1)$, Barrett özofagus kontrolü $(\mathrm{n}=1)$.
Tablo 3. Barret özofagus ve hiatus hernisi varlığı ile İP boyutu arasındaki ilişki

\begin{tabular}{lcc} 
& $\begin{array}{c}\text { IP Boyutu (mm) } \\
\text { Median (min-max) }\end{array}$ & p \\
Barret özofagus (n=6) & $27.5(12-40)$ & 0.004 \\
Var & $10(3-40)$ & \\
Yok & & 0.016 \\
Hiatus hernisi (n=20) & $17.5(4-40)$ & \\
$\quad$ Var & $10(3-40)$ & \\
Yok & & \\
\hline
\end{tabular}

IP: Inlet patch.

\section{TARTIŞMA}

Çalısmamız 245 IP hastası ile bildiğimiz kadarıla ülkemizde yapılmış olan en büyük hasta sayısına sahip retrospektif çalışmadır. 125 (\%51) hastanın biyopsisi mevcuttur ve 98 (\%78.4) hastanın IP tanısı biyopsi ile doğrulanmıştır. Tüm hastaların endoskopik görünümü IP ile uyumludur ve 27 (\%21.6) hastadan alınan biyopsi sonucu skumaoz epitel olarak sonuçlanmıştır. Bu hastaların biyopsisinin uyumlu olmamasinin nedeni proksimal özofagusta endoskop ile pozisyonda kalmanın zor olması ve hastaların bu sırada ögürerek biyopsi alınmasını engellemesi ya da istenilen kolumnar epitelden biyopsi alınamamasından kaynaklanıyor olabilir.

Literatürde IP prevalansına ilişkin değişken değerler bildirilmiştir. En büyük otopsi serisinde (1000 olgu), çocuklarda \%4.5 prevalans gösterilmiştir (7). Proksimal özofagusta daha önce bildirilen IP prevalansı endoskopik çalışmalarda \%0.18 ile \%14 arasında değişmektedir (3). IP prevalansı endoskopistin farkındalı̆̆ ile ilişkilendirilmiş olup prevalans inceleyen endoskopistlerde \%2.27 iken, farkındalığı olmayan endoskopistlerde \%0.29 saptanmıştır (2). Al-Mammari ve ark.'nın yaptığı prospektif çalışmada (1407 vaka), çalışmadan habersiz endoskopist 6/515 (\%1.17), sadece IP şüphelendiği durumlarda dar bant görüntüleme (NBI) yapan endoskopist 4/382 (\%1.05) IP saptarken, rutin NBI ile inceleme yapan endoskopist $17 / 510$ (\%3.33) IP saptamıştır ve rutin NBI ile yapılan incelemenin standart beyaz ışı incelemeye kıyasla IP tespit oranını yaklaşık üç kat arttırdığı gösterilmiştir (14). Endoskopi ünitemize ait IP'nin beyaz sşık ve NBI inceleme ile görünümü Resim 2'de gösterilmiştir. Ülkemizde yapılan çalışmalarda IP prevalansı \%0.4-3.6 arasında değişen oranlarda saptanmıştır (15-19). Bizim çalışmamız da Ege Bölgesi'nde üçüncü basamak bir merkezde yapılmış olup prevalans \%1.24 (245/19738) bulunmuştur.

IP’nin cinsiyetlere göre sıklı̆̆ literatürde farklılık göstermektedir. Erkeklerde daha sık olduğunu gösteren çalışmalar $(19,20)$ olduğu gibi kadın cinsiyette daha sık olduğunu gösteren $(17,18,21)$ çalışmalar da mevcuttur. Çalışmamızda ise 


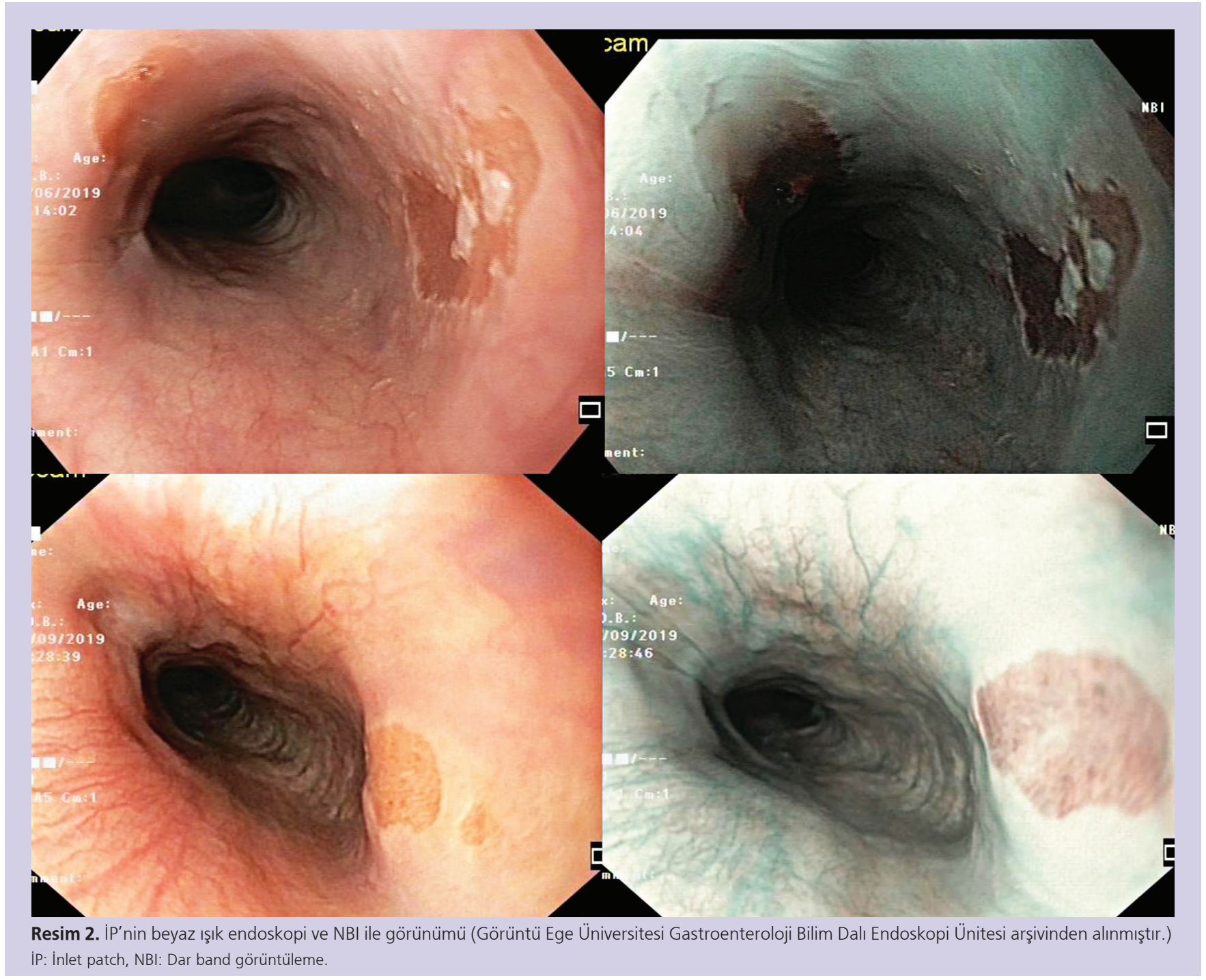

hastaların \%50.6'sı kadın ve \%49.4'ü ise erkektir. Cinsiyet bakımından neredeyse eşit sıklıkta saptanması popülasyonların heterojenliğine ve hasta sayısına göre değişkenlik gösterebilir.

IP 50'li yaşlarda daha sık görülmektedir ve ortalama yaş 55 olarak bildirilmiştir (9). Ülkemizde yapılmış çalışmalarda yaş ortalaması 37.2-57.6 arasında saptanmıştır (17,18,21). Çalışmamızda yaş ortalaması 48.6 saptanmış olup ülkemiz literatürü ile uyumludur. Karşılaştırmalı çalışmalarda yaş aralıklarına göre farklı prevalans bildirilmiş olmakla birlikte çalışmamızın kontrol grubunun olmaması bu açıdan eksiklik saylabilir.

IP sıklıkla asemptomatik olup, dispepsi, reflü hastalığının tipik veya atipik semptomları ve kalıcı globus hissi semptomları ile başvuran hastalarda da endoskopi prosedürleri sırasında fark edilebilir $(2,22)$. IP ile ilişkili diğer semptomlar açıklanamayan ve kalıcı öksürük, ses kısıklığı, odinofaji ve disfajiyi içerir $(4,23)$. Ayrıca, IP için bildirilen laringofarengeal reflü semptomları \%20 ile \%73.1 arasında değişen oranlarda bildirilmiştir (4,24-26). Son zamanlarda yapılan başka bir çalışmada, yüksek IP prevalansına rağmen (239 hastada \%10.9), herhangi bir semptom tipiyle anlamlı bir ilişki olmadığı da gösterilmiştir (27). Daha önce ülkemizde yapılan çalışmalarda dispepsi varlığı \%40.6-\%88.2 arasında değişen oranlarda bulunmuştur $(18,21)$. Çalışmamızda da en sık endoskopi yapılma nedeni \%37.1 ile dispepsi olarak saptanmıştır. Dispeptik hastaların, şikayetlerini açıklayacak bir nedenin bulunmaması kısır bir anksiyojenik döngüye yol açabilir. Ayrıca, hastaya özofagusundaki zararsız ektopik mide mukozasının semptomlarına neden olabileceğini açıklamak, plasebo etkisi yoluyla durumlarının daha iyi yönetilmesine yol açabilir. Bununla birlikte, bir IP belirlendikten ve konjenital bir durum olabileceği bildirildikten sonra hastayla görüşmeler yapmak, onları rahatlatmaya ve semptomatik yüklerini azaltmaya yardimcı olabilir (22). 
IP’lerin BÖ ile ilişkisi birçok çalışmada tartışılmıştır (9). IP ve BÖ arasındaki ilișki üzerindeki çelişkili sonuçlar, etkileşimlerinin büyük ölçüde spekülatif olduğunu göstermektedir $(23,25)$. Bununla birlikte, BÖ ve IP arasındaki patojenik bağ, aynı müsin çekirdeği proteininin ekspresyonu ve sitokeratin paternleri de dahil olmak üzere immünohistolojik benzerlikleri nedeniyle tartısılabilir (28). Avidan ve ark.larının büyük bir vaka kontrol çalışmasında (53 IP ve 4882 kontrol) BÖ'nün IP'li hastalarda, IP'si olmayan kontrol hastalarından 4 kat daha yaygın olduğu bulunmuştur (\%34 vs. \%9) (29). Ülkemizde yapılan çalışmalarda IP hastalarında BÖ sıklığı \%3.5\%13.2 arasında değişen oranlarda saptanmıştır $(17,18,21)$. Bizim çalışmamızda ise BE sıklığı \%2.4 olarak saptanmış olup literatüre göre daha düşüktür.

Literatürde IP ile hitaus hernisi ve eroziv özofajit ilişkisini bildiren çalışmalar mevcuttur. IP'li hastalarda hiatus hernisi sıklığı \%3-\%30.7 arasında bildirilmiştir (4,6,17-19,21,25). Çalışmamızda da IP’li hastalarda hiatus hernisi sıklığı \%8.2 saptanmış olup literatür ile uyumlu bulunmuştur. IP'li hastalarda eroziv özofajit sıklığı \%10.3-\%36.4 arasında bildirilmiştir $(4,6,16-19,21,30)$. Çalışmamızdaki eroziv özofajit sıklı̆̆ \%15.9 olarak saptanmış olup literatür ile uyumludur.

Çalışmamızda endoskopi yapılma nedenleri ve IP boyutu arasında istatistiksel olarak anlamlı farklılık olduğu saptanmıştır. Literatürde IP boyutunun semptomlarla ilişkili olabileceği bildirilmiştir ve bunun muhtemel nedenlerinin artmış asit sekresyonu ve/veya buna bağlı olarak IP'nin distal ucunda- ki darlık olabileceği düşünülmüştür $(31,32)$. Yine literatürde IP'li hastalarda en sık semptomun boyuta bağlı korelasyonu olmayan globus hissi olduğu bildirilmiştir (22). Hori ve ark.'larının yaptığı çalışmada ise globus hissinin non-eroziv reflü hastalığı ile ilişkili olduğu ve daha uzun IP boyutu ve daha büyük toplam IP alanı olan hastalarda globus hissinin daha yaygın olduğu gösterilmiştir (33). Çalışmamızda da \%13.5 hastanın pirozis ve regürjitasyon semptomu mevcut olup, IP boyutu ile endoskopi yapılma nedenleri arasındaki istatiksel anlamlı saptanan ilişkide en büyük boyuta [20 (340) mm] bu grubun sahip olduğu görülmüştür. Retrospektif olarak yapılan çalışmamızda endoskopi yapılma nedenlerinin çoğu klinik ön tanı olarak belirtilmiş olup globus hissi sorgulanamamıștır.

Sonuç olarak, üçüncü basamak bir sağllk kuruluşunda herhangi bir nedenle yapilan endoskopilerin \%1.24'ünde IP saptanmıştır. Merkezimiz tüm Ege Bölgesi’ne sağlık hizmeti vermekte olduğundan, çalışmamızın Ege Bölgesi'nin IP prevalansını yansıttı̆̆ı söylenebilir. Fonksiyonel dispepsi, disfaji, nedeni bilinmeyen kronik öksürüğü ve globusu olan hastalarda, servikal özofagus IP açısından dikkatli bir şekilde incelenmelidir. Daha önce endoskopi yapılmıs olsa bile bu grup hastaların tam sedatize edilerek endoskopi işleminin tekrarlanması ve NBI ile değerlendirilmesi akılda tutulmalıdır.

\section{“Tüm yazarlar herhangi bir çıkar çatışması olmadığını be- yan ederler."}

\section{KAYNAKLAR}

1. Schumidt FFA. De mammlium oesophage atque ventriculo, Inaugural dissertation. Bathenea: Halle, 1805

2. Maconi G, Pace F, Vago L, et al. Prevelance and clinical features of heterotopic gastric mucosa in the upper oesophagus (inlet patch). Eur J Gastroenterol Hepatol. 2000;12:745-9.

3. Peitz U, Vieth M, Evert M, et al. The prevalence of gastric heterotopia of the proximal esophagus is underestimated, but preneoplasia is rarecorrelation with Barrett's esophagus. BMC Gastroenterol 2017;17:87.

4. Jacobs E, Dehou MF. Heterotopic gastric mucosa in the upper esophagus: a prospective study of 33 cases and review of literature. Endoscopy 1997;29:710-5.

5. Lujan G, Genta R. The inlet patch revisited: A clinicopathologic study of 569 patients with heterotopic gastric mucosa in the proximal esophagus. Am J Gastroenterol. 2010;105:S4

6. Weickert U, Wolf A, Schröder C, et al. Frequency, histopathological findings, and clinical significance of cervical heterotopic gastric mucosa (gastric inlet patch): a prospective study in 300 patients. Dis Esophagus 2011;24:63-8

7. Rector LE, Connerley ML. Aberrant mucosa in esophagus in infants and in children. Arch Pathol 1941;31:285.

8. Jabbari M, Goresky CA, Lough J, et al. The inlet patch: heterotopic gastric mucosa in the upper esophagus. Gastroenterology 1985;89:352-6.

9. Tang P, McKinley MJ, Sporrer M, Kahn E. Inlet patch: prevalence, histologic type, and association with esophagitis, Barrett esophagus, and antritis. Arch Pathol Lab Med 2004;128:444-7.
10. Shah KK, DeRidder PH, Shah KK. Ectopic gastric mucosa in proximal esophagus. Its clinical significance and hormonal profile. J Clin Gastroenterol 1986;8:509-13.

11. Rusu R, Ishaq S, Wong T, Dunn JM. Cervical inlet patch: new insights into diagnosis and endoscopic therapy. Frontline Gastroenterol 2018;9:214-20

12. American Gastroenterological Association, Spechler SJ, Sharma P, Souza RF, Inadomi JM, Shaheen NJ. American Gastroenterological Association medical position statement on the management of Barrett's esophagus. Gastroenterology 2011;140:1084-91.

13. Lundell LR, Dent J, Bennett JR, et al. Endoscopic assessment of oesophagitis: clinical and functional correlates and further validation of the Los Angeles classification. Gut 1999;45:172-80.

14. Al-Mammari S, Selvarajah U, East JE, Bailey AA, Braden B. Narrow band imaging facilitates detection of inlet patches in the cervical oesophagus. Dig Liver Dis 2014;46:716-9.

15. Kekilli M, Sayılır M, Yeşil Y, et al. Servikal özofagustaki HGM'nın endoskopik sıklığı; bir referans merkez çalışması. Akademik Gastroenteroloji Dergisi 2009;8:119-22.

16. Akbayır N, Alkim C, Erdem L, et al. Heterotopic gastric mucosa in the servical esophagus (inlet patch): endoscopic prevalence, histological and clinical characteristics. J Gastroenterol Hepatol 2004;19:891-6.

17. Yüksel I, Üsküdar O, Köklü S, et al. Inlet patch: Association with endoscopic findings in the upper gastrointestinal system. Scand J Gastroenterol 2008;43:910-4. 
18. Savaş N, Akbaş E. Heterotopik gastrik mukozanın sıklı̆ı, klinik önemi ve eşlik eden diğer klinik bulgular. Endoskopi Gastrointestinal 2014;22:60-3.

19. Poyrazoğlu OK, Bahçecioğlu IH, Dağlı AF, et al. Heterotopic gastric mucosa (inlet patch): endoscopic prevalence, histopathological, demographical and clinical characteristics. Int J Clin Pract 2009;63:287-91.

20. Takeji H, Ueno J, Nishitani H. Ectopic gastric mucosa in the upper esophagus: prevalence and radiologic findings. AJR Am J Roentgenol 1995;164:901-4.

21. Alagozlu H, Simsek Z, Unal S, et al. Is there an association between Helicobacter pylori in the inlet patch and globus sensation? World J Gastroenterol 2010;16:42-7.

22. Ciocalteu A, Popa P, Ionescu M, Gheonea DI. Issues and cont.roversies in esophageal inlet patch. World J Gastroenterol 2019;25:4061-73.

23. Neumann WL, Luján GM, Genta RM. Gastric heterotopia in the proximal oesophagus ("inlet patch"): Association with adenocarcinomas arising in Barrett mucosa. Dig Liver Dis 2012;44:292-6.

24. von Rahden BH, Stein HJ, Becker K, Liebermann-Meffert D, Siewert JR. Heterotopic gastric mucosa of the esophagus: literature-review and proposal of a clinicopathologic classification. Am J Gastroenterol 2004;99:543-51.

25. Chong VH, Jalihal A. Heterotopic gastric mucosal patch of the esophagus is associated with higher prevalence of laryngopharyngeal reflux symptoms. Eur Arch Otorhinolaryngol 2010;267:1793-9.
26. Bajbouj M, Becker V, Eckel F, et al. Argon plasma coagulation of cervical heterotopic gastric mucosa as an alternative treatment for globus sensations. Gastroenterology 2009;137:440-4.

27. López-Colombo A, Jiménez-Toxqui M, Gogeascoechea-Guillén PD, et al. Prevalence of esophageal inlet patch and clinical characteristics of the patients. Rev Gastroenterol Mex 2019;84:442-8.

28. Lauwers GY, Mino M, Ban S, et al. Cytokeratins 7 and 20 and mucin core protein expression in esophageal cervical inlet patch. Am J Surg Pathol 2005;29:437-42.

29. Avidan B, Sonnenberg A, Chejfec G, Schnell TG, Sontag SJ. Is there a link between cervical inlet patch and Barrett's esophagus? Gastrointest Endosc 2001;53:717-21.

30. Borhan-Manesh F, Farnum JB. Incidence of heterotopic gastric mucosa in the upper oesophagus. Gut 1991;32:968-72.

31. Behrens C, Yen PP. Esophageal inlet patch. Radiol Res Pract 2011;2011:460890.

32. Shimamura Y, Winer S, Marcon N. A giant circumferential inlet patch with acid secretion causing stricture. Clin Gastroenterol Hepatol 2017;15:A22-A23.

33. Hori K, Kim Y, Sakurai J, et al. Non-erosive reflux disease rather than cervical inlet patch involves globus. J Gastroenterol 2010;45:1138-45. 